\title{
Pesquisa e formação na área do meio ambiente e desenvolvimento: novos quadros de pensamento, novas formas de avaliação
}

\author{
Claude RAYNAUT*, Paulo da Cunha LANA**, Magda ZANONI***
}

\begin{abstract}
RESUMO
Este artigo apresenta e discute o referencial conceitual de propostas voltadas para a formação e pesquisa na área do desenvolvimento e meio ambiente. São analisadas com maior detalhe as noções de "desenvolvimento sustentável" e de "interdisciplinaridade", por constarem de todas as formas de expressão da demanda social ambientalista e da maioria dos cursos em Desenvolvimento e Meio Ambiente. Diversos programas de pós-graduação ou pesquisa de caráter interdisciplinar vêm sendo recentemente implantados no Brasil, tentando incorporar esta dualidade conceitual da sustentabilidade e da interdisciplinaridade às suas práticas e reflexões. Esta nova realidade acadêmica, surgida com a criação de cursos interdisciplinares, exige o desenvolvimento de formas de avaliação muito distintas daquelas até então usadas para a análise de programas de cunho disciplinar. O trabalho propõe formas de acompanhamento e avaliação de desempenho, mais coerentes e compatíveis com as estruturas e modos de funcionamento originados destes novos conceitos.
\end{abstract}

Palavras-chave: Desenvolvimento sustentável, Interdisciplinariedade

\begin{abstract}
We present and discuss the conceptual framework of research and formation in the realm of environmental and developmental issues. The widely used concepts of "sustainable development" and "interdisciplinarity" are critically analyzed. Many graduate programs, recently created in Brazil, have tried to incorporate both concepts to their planning and practice. To evaluate such interdisciplinary programs we need new procedures, which may widely differ from the current institutional model, originally planned for disciplinary courses. We propose alternate forms of evaluating the performance of such graduate programs which are more adequate and compatible with the newly created academic structures.
\end{abstract}

Key-words: Sustentable development, Interdisciplinarity

\footnotetext{
* Université Bordeaux2-CNRS/ Doutorado em Meio Ambiente e Desenvolvimento, Universidade Federal do Paraná, R. dos Funcionários, Curitiba, Paraná, Brasil

** Centro de Estudos do Mar/Doutorado em Meio Ambiente e Desenvolvimento, Universidade Federal do Paraná

***Université Paris 7 - Denis Diderot/Doutorado em Meio Ambiente e Desenvolvimento, Universidade Federal do Paraná
} 
RAYNAUT, C.; LANA, P. C.; ZANONI, M. Pesquisa e formação na área do meio ambiente e...

\section{Introdução}

O aparecimento de novas preocupações, conflitos e temas de debate em relação à problemática do meio ambiente e desenvolvimento, tanto no âmbito nacional como internacional, tornou necessária a elaboração de novos paradigmas e de novos conceitos econômicos e legais, visando a descrição e a análise da realidade contemporânea. Ao mesmo tempo, há uma demanda real de profissionais treinados para integrarem esses referenciais incipientes na elaboração e aplicação de estratégias concretas de desenvolvimento, atentas às dimensões ambientais. Novas formas de produção do conhecimento científico, adaptadas para a solução desses problemas, devem ser encontradas. Frente a estas exigências sociais de inovação intelectual, científica e pedagógica, as universidades - e mais amplamente as instituições acadêmicas - se confrontam com verdadeiros desafios.

Como traduzir as demandas da sociedade em conceitos científicos pertinentes?

Que tipos de profissionais formar no quadro das universidades e que recursos pedagógicos adotar para isso?

Como avaliar a qualidade dos cursos de formação, bem como dos documentos científicos por eles produzidos, como artigos e teses?

Estas são algumas das questões que devemos nos fazer, ainda mais nesta época de grandes mudanças sociais e intelectuais. Os velhos quadros de pensamento e os critérios e procedimentos de avaliação há muito estabelecidos deixaram de atender satisfatoriamente estas novas realidades. É necessário encontrar novas formas de atuação nesse domínio sem dar margem para improvisações.

Diversos cursos de caráter interdisciplinar, ou assim nomeados, vêm sendo recentemente implantados no país como reação natural da comunidade universitária brasileira à dificuldade de abordagem da temática do meio ambiente e desenvolvimento a partir de posturas disciplinares de caráter linear ou reducionista, sejam elas naturalistas ou sócio-políticas. A existência destes novos cursos exige, por sua vez, o desenvolvimento de formas de acompanhamento e avaliação que podem diferir grandemente daquelas até então utilizadas para a avalia- ção de programas de cunho disciplinar.

Este artigo procura apresentar e discutir o referencial conceitual destas propostas inovadoras voltadas especificamente para a formação e pesquisa na área do desenvolvimento e meio ambiente. Paralelamente, propõe formas de acompanhamento e avaliação de desempenho, mais coerentes e compatíveis com as estruturas e modos de funcionamento originados destes novos conceitos.

\section{O surgimento da questão ambiental na sociedade contemporânea}

A problemática do meio ambiente começou a ser contemplada na reflexão e nas discussões sobre o desenvolvimento principalmente a partir da década de 70 , após trinta anos de crescimento acelerado da produção econômica dos países industrializados. O debate foi iniciado pelo relatório do Clube de Roma que apontava os limites do crescimento da produção devido ao caráter finito das reservas mundiais de recursos não renováveis, especialmente dos energéticos. No mesmo período, o rápido aumento do preço do petróleo gerou uma crise econômica profunda em todos os países que não tinham recursos próprios e cujo abastecimento energético dependia do exterior. Os países industrializados, principalmente os europeus, com um nível de consumo muito alto, foram duramente atingidos e iniciaram uma mudança profunda da sua economia a fim de reduzir seu grau de dependência energética. Contudo, não modificaram radicalmente seu modelo de desenvolvimento, mantendo como seu objetivo central o crescimento contínuo do padrão de vida da população.

Na mesma época, iniciou-se um outro grande debate, que também dizia respeito à questão dos limites dos recursos disponíveis no mundo, mas salientando os riscos associados ao crescimento populacional. Segundo aquela análise, um aumento contínuo e rápido da população mundial e da demanda de produtos alimentares e de outros gêneros iria induzir uma pressão global excessiva sobre os recursos disponíveis e sobre os sistemas naturais. Isto conduziria a uma crise geral do abastecimento, bem como a uma sobrexploração dos meios 
naturais, com todas as conseqüências associadas. Como os países industrializados tinham uma taxa de crescimento baixa, até próxima de zero, o debate concentrouse principalmente nos países em desenvolvimento e na necessidade de que estes aplicassem uma rigorosa política de controle da natalidade. Uma análise tão mecanicista da realidade sócio-econômica mundial, desconsiderando a diferença enorme do nível de consumo entre países industrializados e em desenvolvimento, gerou inúmeros embates nas instituições e conferências internacionais, embora os países publicamente mais opostos a essas recomendações, como a China, as aplicassem no seu próprio território.

Estes diagnósticos sobre as relações entre as sociedades contemporâneas e seu ambiente se mantinham em um nível muito genérico. O que poderia definir essa etapa da reflexão era a tomada de consciência, pela primeira vez na história da humanidade, do caráter finito do mundo em que vivemos e de seus recursos. No entanto, algumas crises ambientais de caráter regional ou local começaram a chamar atenção, tanto dos políticos como dos cientistas, sobre a pertinência de outras escalas de análise das relações entre as populações e o seu meio natural. Uma delas, apesar de quase desconhecida na América Latina, teve uma grande influência no amadurecimento da reflexão sobre a multiplicidade dos fatores que concorrem para o aparecimento de uma situação de crise ambiental localizada e sobre a complexidade das estratégias econômicas, técnicas e sociais a serem aplicadas para solucioná-la. Trata-se da crise do Sahel africano, formado pelos países da faixa subdesértica que se estendem ao longo do deserto do Saara, atravessando o continente desde o oceano Atlântico até o Índico. Desde os primeiros anos da década de 70, estes países têm experimentado uma sucessão de quedas de produção e de episódios de fome, acompanhados da morte de milhares de pessoas e de centenas de milhares de cabeças de gado. Áreas enormes, antes ocupadas por florestas, tornaram-se quase desertas. O componente climático desses acontecimentos é indiscutível, mas não explica tudo. Só a conjunção e a interação de muitos fatores - climáticos, demográficos, técnicos, políticos, econômicos e sociais - podem dar conta da amplitude e da duração dessa crise (Raynaut et al,. 1997). Graças a uma mobilização sem precedentes das entidades de ajuda internacional, programas de pesquisa e programas de desenvolvimento foram lançados em todos os países da área. Seus objetivos eram tentar entender melhor as dimensões locais daquela crise global e achar soluções adequadas para permitir que as sociedades locais sobrevivessem e se desenvolvessem num ambiente natural difícil e frágil, aplicando práticas técnicas adaptadas para dar fim às dinâmicas de desertificação e, se possível, recuperar setores já degradados. Poucos destes programas conseguiram resultados concretos e duráveis, mas todos participaram da elaboração de um novo enfoque do desenvolvimento rural, mais aberto à consideração da diversidade das situações locais e da complexidade das relações entre as sociedades humanas e o seu ambiente e por conseguinte mais consciente da necessidade de um enfoque pluridisciplinar. A noção de "pacote tecnológico", herança da chamada "revolução verde", mostrou-se particularmente inadequado nessas circunstâncias. Apesar da sua posição marginal no palco político e econômico internacional, o Sahel teve um papel importante na mudança dos paradigmas do desenvolvimento local das grandes organizações internacionais, tais como o Banco Mundial e o Programa das Nações Unidas para o Desenvolvimento.

No decorrer das três últimas décadas do século 20, muitas outras situações de crises ambientais locais foram identificadas, muitas delas no Brasil, caso da Amazônia, do Nordeste e da Mata Atlântica). Ao mesmo tempo, o fenômeno da poluição tornou-se mais identificado, tanto em relação a seus impactos locais e diretos (ameaças sobre a saúde humana, eutrofização, destruição de áreas frágeis etc) como globais e indiretos (efeito estufa, destruição da camada de ozônio, subida do nível do mar etc). As inquietações ligadas ao meio ambiente passaram a ser progressivamente uma das preocupações centrais da opinião pública dos países industrializados e das faixas mais bem sucedidas das populações dos países em desenvolvimento. Tornaram-se também um elemento crítico na elaboração das políticas públicas do fim do século. No Brasil, iniciou-se a partir dos meados da década 70 um movimento ecológico pujante e a questão ambiental passou a ser um assunto político central (Viola, 1987). A Conferência do Rio, organizada em 1992, foi 
RAYNAUT, C.; LANA, P. C.; ZANONI, M. Pesquisa e formação na área do meio ambiente e...

uma expressão da importância que o tema já tinha assumido para a classe política brasileira, bem como um incentivo para uma mobilização ainda maior dos interesses públicos e privados nesse domínio.

\section{A busca de um novo quadro conceitual: sustentabilidade e interdisciplinaridade}

Para empreender qualquer tipo de avaliação de uma atividade de caráter científico - tanto no domínio da pesquisa como no da formação - é preciso definir o referencial conceitual em função do qual a coerência de objetivos dos cursos serão analisados. Não se trata de impor uma linha teórica hegemônica num contexto onde muito ainda está para ser construído, mas sim de estabelecer alguns marcos comuns, de criar um consenso mínimo sobre a maneira de abordar alguns conceitos-chave. Não se trata de procurar uma definição única, mas de definir as margens de variação aceitáveis para manter critérios de avaliação comuns.

Duas noções básicas são prioritárias neste esforço inicial de harmonização, por constarem de todas as formas de expressão da demanda social ambientalista e de qualquer curso em Desenvolvimento e Meio Ambiente. São aquelas de "desenvolvimento sustentável" e de "interdisciplinaridade". Ambas têm atualmente um uso tão geral e banalizado que muitas vezes mais se assemelham a invocações rituais do que a conceitos com acepções claramente definidas. Um trabalho aprofundado de crítica e esclarecimento dessas noções é necessário para todos os que as utilizam numa perspectiva científica.

\section{Reformulando a demanda social: o desenvolvimen- to sustentável}

A noção de sustentabilidade ou de durabilidade se origina de teorizações e práticas ecológicas que tentam analisar a evolução temporal de recursos naturais, tomando por base a sua persistência, manutenção ou capacidade de retorno a um presumido estado de equilíbrio, após algum tipo de perturbação. A noção de equilíbrio é tema polêmico e controverso, mesmo no domínio ecológico, já que os sistemas naturais, incluídos neles os chamados recursos renováveis, estão sujeitos a elevada variabilidade, expressa em distintas escalas temporais e espaciais.

A tentativa de incorporação do conceito de sustentabilidade às políticas de desenvolvimento é fato relativamente recente. Até o início da década de 70, as estratégias globais de desenvolvimento, mesmo aquelas denominadas integradas, não contemplavam especificamente a problemática do meio ambiente ou do uso continuado de seus recursos. Pelo contrário, as agendas conservacionistas eram vistas como esforços contrários aos planos de desenvolvimento, que tinham a valorização dos espaços e dos recursos inexplorados como seus esteios básicos, através da industrialização, da modernização da agricultura, da urbanização e da transferência de tecnologias. Sob esta ótica, a natureza não representava um custo, mas existia para ser modificada e valorizada.

Nos anos 70, a pauta ambiental já estava presente e era uma das principais condicionadoras da idéia de "ecodesenvolvimento", sugerida por Maurice Strong e sistematizada por Sachs (1980), como um

desenvolvimento endógeno e dependendo de suas próprias forças, submetido à lógica das necessidades do conjunto da população, consciente da sua dimensão ecológica e buscando estabelecer uma relação de harmonia entre o homem e a natureza.

A disseminação do conceito de ecodesenvolvimento foi explosiva, como demonstrado pelas reflexões e ações do próprio Programa das Nações Unidas para o Meio Ambiente e pela proliferação de unidades de pesquisa e teorização em todo o mundo (Zanoni e Raynaut, 1994).

Esse conceito de ecodesenvolvimento tinha um caráter evidentemente axiomático e normativo, como se a solução dos problemas ambientais se resumisse ao controle de um crescimento econômico anárquico e a uma proteção rigorosa da natureza, frente às agressões humanas. Propunha um modelo de desenvolvimento a ser aplicado para viabilizar uma relação "harmoniosa" en- 
tre o homem e a natureza - a busca de um paraíso perdido. O conceito de "desenvolvimento sustentável" emergiu daquele de ecodesenvolvimento, introduzindo ainda mais imprecisão do que antes. Cerca de 60 definições diferentes da noção têm sido identificadas (Latouche, 1995). Esteve, em sua origem, estreitamente ligado à idéia de conservação, tal como preconizada pela União Internacional para a Conservação da Natureza em sua Estratégia Mundial da Conservação. Nesta acepção, a conservação era vista como o manejo da biosfera de tal modo a garantir os maiores benefícios sustentáveis para as presentes gerações, sem colocar em risco o atendimento das necessidades e aspirações das futuras gerações. Este mesmo documento definia o desenvolvimento como a modificação da biosfera e a aplicação de recursos humanos, financeiros, vivos e não vivos para satisfazer as necessidades e melhorar a qualidade de vida dos homens. Estas duas definições, aparentemente incompatíveis, foram fundidas, dando origem ao conceito de desenvolvimento sustentável ou durável. Este emergiu no contexto da conferência de Cocoyoc, mas se tornou mundialmente conhecido através do Relatório Brundtland (1987). O conceito, tal como originalmente formulado, tinha mais valor retórico do que prático e referia-se a um desenvolvimento que satisfaz as necessidades da geração atual, sem comprometer a capacidade das gerações futuras de satisfazer as suas. O conceito de desenvolvimento sustentável encontrou ampla ressonância na sociedade e esteve no âmago do debate da Conferência do Rio, em 1992, cuja carta incorporou uma noção modificada das estratégias de desenvolvimento, vistas agora como mudanças ou "progressos" tendo por base a exploração de recursos naturais, mas limitados ou condicionados pela própria estabilidade ou reprodutibilidade destes recursos.

A própria idéia de sustentabilidade se apoia numa representação da realidade fortemente dependente da noção de um presumido "equilíbrio" tanto natural como social. Neste sentido, o conceito é passível de críticas, tanto no domínio ecológico quanto no domínio das esferas de regulação social e econômica, que tendem a aceitar e incorporar cada vez mais as noções de variabilidade, incerteza e irreversibilidade nas dinâmicas dos sistemas (Weber, 1997). É atualmente bem claro que a noção de equilíbrio consta mais do domínio dos modelos axiomáticos e das esperanças sociais do que dos instrumentos conceituais utilizáveis para analisar a realidade. Para pretender uma fundamentação teórica sólida, toda reflexão sobre o desenvolvimento sustentável deve ultrapassar uma utilização ingênua das noções de equilíbrio/desequilíbrio - tais como constam da demanda social - e incorporar as considerações científicas mais recentes sobre as dinâmicas permanentes dos sistemas tanto naturais como sociais.

Até hoje, o conceito de desenvolvimento sustentável permanece muito ambíguo. Ele pode ser referido a domínios diferentes da realidade (físico-natural versus social e econômico) e utilizado para níveis de análise totalmente diferentes, tanto globais (como o aquecimento do clima do globo) como locais (preservação de uma área protegida). $\mathrm{O}$ conceito pode, também, contemplar escalas de tempo muito diferentes, desde a das gerações presentes até aquela das gerações futuras. Isto tem acarretado conflitos e embates entre os que usam a expressão com sentidos diferentes, embora estas contradições e incoerências permaneçam dissimuladas atrás de um aparente consenso.

Em resumo, a noção de desenvolvimento sustentável é o produto de um processo histórico de construção social. É uma forma de expressão da demanda social. Como tal, incorpora um conjunto de elementos, alguns oriundos do campo científico, outros das experiências passadas no domínio do desenvolvimento, outros também dos embates sociais e políticos que se desenvolvem em varias escalas nacionais e internacionais. Para tornar essa noção um instrumento pertinente no campo da ciência, é preciso criticá-la e reformulá-la tanto do ponto de vista conceitual como metodológico. Isso é uma exigência que se impõe a todos os cientistas que pretendem dela se valer. Nessa fase inicial de estruturação de um novo campo cientifico, é indispensável levar em conta as várias interpretações existentes da sustentabilidade. Uma vez que se trata da produção de um conhecimento científico e da formação de profissionais cuja atuação se assentará em competências científicas, é preciso exigir que esse trabalho de reformulação seja devidamente cumprido. 
RAYNAUT, C.; LANA, P. C.; ZANONI, M. Pesquisa e formação na área do meio ambiente e...

Reformulando a demanda intelectual: o conceito da interdisciplinaridade

O interesse epistemológico principal do conceito de desenvolvimento sustentável reside na sua tentativa de integrar as dinâmicas ligadas ao meio natural e as dinâmicas ligadas às sociedades humanas. Pretende, por definição, ser uma noção integradora. Por isso, uma das características principais dos cursos de pós-graduação voltados para os problemas de desenvolvimento e meio ambiente deveria ser um esforço comum para incorporar esses dois domínios dentro do processo de produção do conhecimento e de formação. A noção de "interdisciplinaridade" passa, portanto, a ocupar uma posição central na atuação científica e nas concepções pedagógicas desses cursos.

Esta noção está também sujeita a tantos debates e interpretações que um trabalho de esclarecimento é imprescindível para quem for usá-la. Aqui, também, podem ser identificados dois pólos extremos entre os quais oscila a discussão sobre o recorte disciplinar e as relações entre as disciplinas. O ponto de partida pode ser uma crítica do processo histórico responsável pelo aparecimento da ciência moderna e pela diferenciação disciplinar. Essa crítica aponta para o fracionamento do conhecimento, a criação de domínios compartimentalizados, como resultado de uma busca sempre crescente de eficácia técnica e operacional. As conseqüências dessa evolução são muitas. Os saberes científicos são cada vez mais especializados, sem relações entre si, de tal maneira que faltam agora os instrumentos intelectuais para uma visão global da realidade, já que o recorte disciplinar não pode dar conta da sua unidade ontológica. Em conseqüência, as formas prevalecentes de ensino, particularmente no nível da pós-graduação, se baseiam numa crescente e progressiva especialização. Esta tendência torna cada vez mais difícil a comunicação e a colaboração entre os praticantes das diversas disciplinas.

Esta consideração tem alcance geral, mas torna-se particularmente pertinente no domínio da problemática ambiental, onde o divórcio entre as ciências humanas e as ciências físicas e naturais prejudica de maneira evidente a capacidade de entender as dinâmicas complexas em operação. Como reação a tal estado de coisas, são cada vez mais freqüentes as tentativas de se encontrar novas estratégias epistemológicas para a construção de uma racionalidade ambiental que reintegre este conhecimento multifacetado e facilite a abordagem dos graves conflitos ambientais que vivemos.

Baseada nessa crítica, surgiu o projeto epistemológico de dar cabo deste fracionamento, de ultrapassar as fronteiras disciplinares e de estabelecer as condições de constituição de um saber unificador ou "transdisciplinar" (Morin, 1997). Por mais intelectualmente legítimo que seja, este projeto encontra muitas dificuldades para ultrapassar uma retórica axiomática e propor procedimentos concretos de construção do conhecimento científico que não sejam ligados a práticas disciplinares particulares. Encontra sua manifestação em trabalhos de pesquisa, livros e teses que pretendem manipular e misturar paradigmas, conceitos e saberes, oriundos de várias ciências, ultrapassando as fronteiras entre as disciplinas. Os limites e os riscos desta posição epistemológica têm sido salientados com muita ênfase (Sokal e Bricmont, 1997).

O outro pólo das concepções do relacionamento entre as disciplinas não questiona o recorte disciplinar. Ele é considerado como um mosaico de olhares complementares que, associados, podem reconstituir a complexidade da realidade nas suas várias dimensões. Para analisar uma situação ambiental, bastaria então reunir um conjunto de disciplinas cujo leque abrangesse os principais tipos de problemas nela colocados, como os naturais, técnicos, sociais e econômicos. Contudo, a experiência prática dos programas de pesquisa mostra que, na realidade, as dificuldades encontradas para estabelecer trocas entre as disciplinas - especialmente entre as ciências sociais e as naturais - são muito grandes quando falta uma problemática comum e um acerto metodológico entre as disciplinas no que se refere às escalas de análise adotadas e aos objetos de estudos escolhidos. A articulação entre as disciplinas não se faz espontaneamente, mas tem de ser construída de maneira sistemática.

A partir das constatações originadas de experiências concretas (Dobremez et al., 1990 ; Jollivet e Pavé, 1993; Raynaut, 1994 ; Raynaut, 1997), emergiu uma outra abordagem de colaboração entre as disciplinas, com uma 
preocupação primária centrada nos procedimentos metodológicos de articulação e interação entre cientistas que atuam em campos disciplinares diferentes, com paradigmas e modelos conceituais distintos, praticando escalas de análise e práticas metodológicas também heterogêneas. Estas experiências evidenciam o fato que uma interdisciplinaridade efetiva entre cientistas oriundos de campos diferentes do saber só pode ser alcançada através de um processo metódico de construção. Isto implica em primeiro lugar, se não o estabelecimento de uma linguagem comum, aos menos uma compreensão mútua dos conteúdos diferentes atribuídos por vários especialistas a conceitos aparentemente idênticos por eles utilizados por conta própria. Em segundo lugar, exige a elaboração de um quadro problemático central, em torno do qual cada pesquisador vai construir sua própria problemática disciplinar. A partir deste trabalho prévio, torna-se possível organizar um plano de trabalho coletivo, precisando-se quais são as operações de pesquisa comuns a serem realizadas, quais são as operações disciplinares assim como o cronograma destas operações. Neste processo, uma condição essencial para possibilitar uma articulação final dos resultados obtidos em diferentes campos disciplinares é uma definição consensual dos objetos de estudo e das escalas da observação. Estas são as condições essenciais para o sucesso de um programa de pesquisa interdisciplinar. Este processo de construção de um saber científico não pretende soltar-se do recorte disciplinar, mas sim valer-se das competências de cada especialista atuando no seu próprio campo e organizando-as de maneira sistemática.

\section{A formação acadêmica: novas exigências, no- vas experiências pedagógicas}

O debate sobre a sustentabilidade, particularmente quando deixa o domínio da ampla e generosa retórica ambientalista para se focar nas ações cotidianas, seja na pesquisa, formação ou extensão, deve assumir um enfoque mais científico e pragmático. Para tal, deve considerar a diversidade e a complexidade das relações entre as sociedades humanas e seu meio ambiente. Há a exigência de elaboração de um quadro metodológico adequado, que dê origem, por sua vez, a um conhecimento que permita analisar problemas locais e tentar achar soluções para estes. Isto afeta diretamente tanto o campo da pesquisa como o do ensino ou formação acadêmica.

Por sua vez, a visão interdisciplinar parte da premissa de que todas as práticas humanas comportam dimensões objetivas, evidenciadas pelas dinâmicas naturais e pelas práticas técnicas, além da dimensão das representações e do imaterial, expresso por relações simbólicas. A aceitação desta dualidade e sua incorporação, na prática, a programas de formação universitária, gera estruturas e processos acadêmicos que são forçosamente distintos da maioria dos modelos ora vigentes no ensino de pós-graduação.

Frente a esta diversidade, a primeira exigência para os cursos de formação de especialistas que vão trabalhar no campo do "desenvolvimento sustentável", com base em pressupostos "interdisciplinares", é que forneçam uma definição clara dos conceitos que utilizam. No entanto, essa definição não deve permanecer como mera retórica de conteúdo axiomático e normativo. Deve precisar as condições de sua aplicação no quadro de um enfoque científico que detalhe as escalas de análise adotadas e que articule objetos de estudo bem definidos, com suas próprias hipóteses de trabalho e seus próprios métodos de observação e teste crítico.

Neste contexto, o principal objetivo de um curso interdisciplinar na área do meio ambiente e desenvolvimento é a formação de profissionais que, conservando e reafirmando suas competências disciplinares, sejam capazes de dialogar e interagir com outros especialistas na abordagem concreta das relações sociedade-natureza a partir de modelos conceituais, hipóteses e procedimentos metodológicos comuns, reforçados pelas heterogêneas escalas de análise e práticas metodológicas provenientes dos distintos campos disciplinares envolvidos. Não devem ser necessariamente perseguidas uma "linguagem comum" ou a formação de generalistas presumidamente dotados de uma competência universal, autosuficiente e retoricamente desvinculada do conhecimento disciplinar. A formação concebida deve possibilitar a cada participante, incluindo tanto docentes como discentes, a convivência e interação com outros modos de 
RAYNAUT, C.; LANA, P. C.; ZANONI, M. Pesquisa e formação na área do meio ambiente e...

apreensão do real, paralelamente ao reforço de sua própria área de conhecimento.

A necessária prática interdisciplinar só ganhará significado com a prática social e a intervenção no real. Neste sentido, a temática do meio ambiente e do desenvolvimento tem uma dimensão social que transcende as atividades puramente acadêmicas da formação universitária. A formação ideal deve ser sensível às múltiplas demandas sociais que refletem, por sua vez, as contradições, corporativismos e conflitos da sociedade, do Estado e de seus organismos. Um curso que se pretende interdisciplinar não pode deixar de criar o espaço intelectual para a prática da reflexão e para a prática social, lastreando-se em programas de pesquisas que envolvam docentes e discentes na abordagem concreta de problemas de desenvolvimento e meio ambiente.

\section{A evolução recente da formação ambiental no país}

Diversos programas de pós-graduação ou programas de pesquisa de caráter interdisciplinar vêm sendo recentemente implantados no país, tentando incorporar a dualidade conceitual da sustentabilidade e da interdisciplinaridade às suas práticas e reflexões. Esta é uma reação natural da comunidade universitária brasileira à dificuldade do trato da questão ambiental a partir de posturas disciplinares naturalistas ou sócio-políticas estritas. Concepções puramente naturalistas ou sóciopolíticas da questão ambiental são ainda hegemônicas nos nossos meios acadêmicos. Do lado das ciências naturais, a ecologia tem freqüentemente se concebido como a disciplina por excelência das relações homem-natureza. Com freqüência acima da desejável, as principais vertentes ecológicas têm pensado o homem e as formações sociais resultantes unicamente como populações biológicas inseridas no processo evolutivo dos ecossistemas. Esta visão reducionista transforma a ecologia em uma ciência das ciências e numa verdadeira teoria geral dos sistemas. Este funcionalismo sistêmico, que também reflete a visão ambiental de muitas das ciências sociais, é ideologicamente perverso e ambíguo.

Neste momento, existem distribuídos pelo país cerca de 30 cursos de pós-graduação, em nível de espe- cialização, mestrado e doutorado, que se auto-definem como cursos de meio ambiente e/ou desenvolvimento ou de gestão ambiental. Desde o início da década de 90, o aparecimento e desenvolvimento destas iniciativas têm sido literalmente explosivos. Entre as universidades públicas, existem hoje cursos de pós-graduação, em senso estrito, implantados na Universidade Federal do Pará, Universidade de Brasília, Universidade de São Paulo, Universidade Federal da Paraíba, Universidade Federal de Santa Catarina, Universidade Federal do Paraná, Universidade Federal Rural do Rio Grande do Norte, Universidade Federal de Recife, Universidade Federal do Rio Grande do Norte, Universidade Estadual de Santa Cruz (Bahia), Universidade de Campina Grande, Universidade Federal Fluminense, Universidade Federal de Pernambuco, Universidade Federal de Alagoas etc. Estes cursos são freqüentemente inter-departamentais e inter-institucionais. Por sua vez, esta estruturação acadêmica tem gerado dezenas e dezenas de programas de pesquisa que também se definem como interdisciplinares, congregando pesquisadores das mais diversas formações em torno de objetivos comuns. A maioria destes programas têm particular relevância socio-economica e profundas implicações para o desenvolvimento regional e nacional.

\section{O problema de avaliação dos cursos interdisciplinares}

Quaisquer critérios de avaliação de desempenho acadêmico, independentemente da natureza dos cursos, sejam eles disciplinares ou interdisciplinares, devem prioritariamente considerar se os objetivos de ensino, pesquisa e extensão foram cumpridos. Neste contexto, os quarenta anos de pós-graduação do Brasil contam hoje com um sistema de avaliação sólido e amadurecido, basicamente conduzido pela Coordenação de Aperfeiçoamento do Pessoal de Nível Superior (CAPES). No entanto, tais formas de avaliação não deixam de sofrer distorções e nem sempre se pautam pelos ditames de uma política científica em sentido estrito.

A nova realidade acadêmica, surgida com a criação de cursos interdisciplinares, exige o desenvolvimen- 
to de formas de avaliação muito distintas daquelas até então usadas para a análise de programas de cunho disciplinar. Até muito recentemente, a CAPES e o CNPq têm tratado e avaliado as questões ambientais nos seus comitês da área ecológica ou, mais raramente, em comitês da área das ciências sociais. Estes procedimentos têm gerado sérias distorções e equívocos conceituais, com a desnecessária penalização de propostas interdisciplinares, avaliadas sob a ótica bem intencionada, mas limitada, de visões disciplinares naturalistas ou sócio-políticas.

A CAPES utiliza para seus processos de avaliação as denominadas "fichas de avaliação do programa", geradas, por sua vez, detalhados relatórios anuais, preparados pelas coordenações dos cursos e sistematizados no programa DATACAPES. Tais fichas, utilizadas como documentos básicos pelos comitês de avaliação, organizados em áreas do conhecimento, são abrangentes e detalhadas. Contemplam a proposta dos programas, com análises de sua coerência e consistência, adequação das linhas de pesquisa, adequação do corpo docente, existência e importância de intercâmbios nacionais e internacionais, adequação e abrangência das linhas de pesquisa, grau de participação docente e discente, natureza da estrutura curricular, grau de aderência do corpo docente ao programa etc. Neste sentido, embora os critérios de aferição de cada item permaneçam freqüentemente quantitativos, as fichas deveriam permitir avaliações abrangentes e detalhadas do potencial e da excelência acadêmica dos programas de pós-graduação. Paradoxalmente, embora conte com este excelente sistema de informação e com uma excepcional base de dados a respeito da vida acadêmica da pós-graduação, a CAPES vem priorizando o tempo médio dos doutoramentos e mestrados e a produtividade científica total, comumente aferida por critérios meramente quantitativos, como os critérios básicos de avaliação da pós-graduação no país. Tais critérios são cabíveis e imprescindíveis e, como tal, parte importante dos processos de avaliação, ainda mais em um país caracterizado por enormes heterogeneidades sociais, que se refletem necessariamente em heterogeneidades no espaço da pesquisa e da formação nas instituições universitárias. No entanto, "tempo" e "quantidade" não devem ser as diretrizes básicas ou únicas dos processos de avaliação, sob pena de sujeitarem a política nacional de pós-graduação, de forma não crítica, às políticas macro-econômicas governamentais e não à uma política científica saudável e instigadora.

Processos de avaliação coerentes com as propostas interdisciplinares ora em andamento no país deveriam levar em conta uma série de outros indicadores:

\section{No que se refere à caracterização e produção do corpo docente.}

Os recursos humanos disponíveis para a condução do programa são adequados para responder aos desafios teóricos e metodológicos inerentes à abordagem interdisciplinar, em particular associando especialistas das ciências naturais, das ciências sociais e das disciplinas técnicas? A produtividade do corpo docente, além de suprir as exigências de qualidade da sua disciplina é condizente com tal abordagem e testemunha de um real esforço de diálogo e colaboração com outras disciplinas? Está diretamente relacionada com a problemática ambiental ou denota sensibilidade à questão?

O curso desenvolveu mecanismos para a seleção, treinamento e aperfeiçoamento do seu próprio corpo docente? O corpo docente é estimulado a se reunir regularmente para a discussão e integração das atividades de ensino, pesquisa e extensão?

O curso tem uma interação significativa com outros programas de formação e pesquisa, considerandose que a complexidade e diversidade da temática ambiental e do desenvolvimento praticamente impedem a existência de auto-suficiência acadêmica em uma única unidade universitária? Em outras palavras, a participação de pesquisadores e professores de outras instituições é significativa, regular e permanente?

\section{No que se refere à estrutura curricular}

Existe uma participação permanente e ativa de docentes e discentes no processo de montagem, avaliação e readequação da estrutura curricular?

O curso fornece os fundamentos de base necessá- 
rios para a colaboração e intercâmbio entre disciplinas? Em outras palavras, os alunos serão capazes de compreender a linguagem, os objetos e os métodos das outras disciplinas, a fim de poder dialogar a colaborar com elas, na tentativa de compreensão e gestão de questões ambientais e de desenvolvimento?

$\mathrm{O}$ curso fornece os instrumentos e mecanismos conceituais e metodológicos que permitam a reflexão e a prática sobre as relações interdisciplinares e não apenas sobre os objetos disciplinares? Quais são estes instrumentos e mecanismos?

O curso é capaz de realocar estes conhecimentos e instrumentos em um quadro teórico mais amplo, permitindo a cada aluno situar sua contribuição disciplinar específica para análises concretas das relações sociedades-natureza?

3. No que se refere às atividades de pesquisa e extensão

O curso fornece os instrumentos operacionais para a realização do trabalho em equipe e para a prática concreta do diálogo entre disciplinas? Em outras palavras, o curso é bem sucedido na organização dos procedimentos da pesquisa coletiva, através de discussões regulares e de atividades permanentes de campo?

O curso propicia a participação efetiva de docentes e discentes em programas de pesquisa integrados que se configurem como práticas concretas da interdisciplinaridade?

O perfil dos especialistas formados é adequado ou responde às necessidades da universidade, do Estado e das sociedade em geral, no que se refere à análise, concepção e proposição de programas de desenvolvimento?

Por outro lado, o caráter multicêntrico e complexo da temática ambiental exige que o acompanhamento e avaliação de programas de formação e pesquisa sejam conduzidos por equipes com perfil diversificado, envolvendo especialistas das áreas das ciências humanas, sociais e naturais, sensibilizados pelas questões do meio ambiente e desenvolvimento. A CAPES foi sensível ao problema, criando há aproximadamente dois anos, um comitê de Meio Ambiente, de formação multidisciplinar, composto por sociólogos, antropólogos, agrônomos, ecólogos, biólogos etc., envolvidos profissionalmente com a temática ambiental. Com isto, abandonou a prática de delegar as avaliações desta área ao Comitê de Ecologia e Limnologia. O problema ainda persiste no CNPq, em abril de 2000.

\section{Conclusão}

O campo do meio ambiente e do desenvolvimento abre hoje, para o ensino e a pesquisa, um novo espaço conceitual e metodológico. Constitui necessariamente, e assim permanecerá pelos próximos anos, um território de inovação científica e pedagógica. Como todo processo intelectual criador, quando vem de encontro às dúvidas e as inquietações da sociedade, exerce uma imensa atração e mobiliza aspirações e energias muito heterogêneas na sua inspiração bem como na sua manifestação.

Nestas circunstâncias, é conveniente criar nos meios acadêmicos uma dinâmica que possa contribuir para a renovação das formas de produção do conhecimento. Ao mesmo tempo, é preciso definir um referencial científico que permita assegurar a pertinência, a objetividade e o rigor destas numerosas iniciativas acadêmicas hoje em curso no âmbito do desenvolvimento sustentável e da interdisciplinaridade.

Para atingir estes objetivos, é absolutamente essencial readequar-se os dispositivos de avaliação e de acompanhamento ora vigente no sistema de pós-graduação do país. Os procedimentos aplicados no passado, apesar de sua eficácia no campo disciplinar, não dão conta desta nova necessidade. Em particular, deixam de fora critérios de avaliação adequados para a pedagogia e prática de pesquisa interdisciplinares. Tentamos neste trabalho, com base em várias experiências - incluída a nossa própria experiência de mais de 6 anos no quadro do doutorado em Meio Ambiente e Desenvolvimento da UFPR - abrir a discussão sobre o assunto e adiantar algumas propostas. Esperamos que estes elementos sejam o início de um debate científico a ser desenvolvido no futuro. 


\section{REFERENCIAS}

BRUNDTLAND G. H. Our Common Future. Oxford: Oxford University Press, 1987.

DOBREMEZ J. F.; JOLLIVET, M.; RAYNAUT C. et al. Pour une pratique de l'interdisciplinarité. Sciences de la Nature, Sciences de l'homme : dix annés d'expérience au CNRS. Paris: CNRS, 1990.

JOLLIVET, M.; PAVÉ, A. L'environnement: un champ de recherche en formation. Natures, Sciences, Societés, v. 1, p. 6-20, 1993.

LATOUCHE S. La mégamachine. Raison techno scientifique, raison économique et mythe du progrés. Paris: La Découverte, 1995.

MORIN, E. La méthode. 1. La nature de la nature. Paris: Éditions du Seuil, 264 p.

RAYNAUT, C. (Org.). Sahels. Diversité et dynamique des relations sociétés/nature. Paris: Éditions Khartala, 430p., 1997.

RAYNAUT, C. Le développement et les logiques du changement: la necessité d'une approche holistique. Cadernos de Desenvolvimento e Meio Ambiente.
Curitiba: Editora da Universidade Federal do Paraná. v. 1, p. 105-129, 1994.

SACHS, I. Stratégies de l'écodevelopement. Paris: Les Editions Ouvrières, 1990.

SOKAL A.; BRICMONT J. Impostures intellectuelles. Paris: Editions Odile Jacob, 1997.

VIOLA E. J. O movimento ecológico no Brasil (1974-1986): do ambientalismo à ecopolítica. In: PADUA, J. A (Org.). Ecologia e Política no Brasil, 1987.

WEBER, J. Gestão de recursos renováveis: fundamentos teóricos de um programa de pesquisas. In: VIEIRA, Paulo Freire; WEBER, Jacques (Orgs.). Gestão de recursos naturais renováveis e desenvolvimento. Novos desafios para a pesquisa ambiental. São Paulo: Editora Cortez, p. 115-146, 1997.

ZANONI, M.; RAYNAUT, C. Meio ambiente e desenvolvimento: imperativos para a pesquisa e a formação. Reflexões em torno do doutorado da UFPR. Cadernos de Desenvolvimento e Meio Ambiente, Universidade Federal do Paraná, v. 1, p. 143-165. 